\title{
El Salvador de 1970 a 1990: política, economía y sociedad
}

En las últimas tres décadas —de 1970 a 1990 -, se han suscitado en El Salvador cambios políticos, económicos y sociales cuyo sentido global muchas veces escapa a la comprensión de quienes se interesan por los derroteros del país. Una visión global del proceso histórico salvadoreño de las últimas tres décadas no puede dejar de remitirse a los tres grandes ejes que la articulan: (a) la conflictividad sociopolítica que caracterizó la vida nacional durante las décadas de 1970 y 1980; (b) la reestructuración de la economía que comenzó a adquirir perfiles definidos durante la década de 1980 y que se ha continuado en la década de 1990; y (c) el proceso de democratización política que se comenzó a gestar a inicios de la década de 1980, y que obtuvo un impulso decisivo con la firma de los acuerdos de paz (1992). En las páginas que siguen haremos un análisis de esos dinamismos.

\section{La conflictividad sociopolítica}

Desde mediados de la década de los cuarenta hasta el estallido de la guerra civil y su finalización, el proceso histórico salvadoreño estuvo atravesado por fuertes tensiones entre los actores sociopolíticos y económicos del país. En repetidas ocasiones, esas tensiones se tradujeron en crisis sociopolíticas marcadas por la confrontación entre aquellos que daban vida a las lógicas contradictorias: las clases medias, cuyos miembros más lúcidos —estudiantes, profesores, empleados- asumían y daban expresión al malestar de la sociedad ante los diversos tipos de exclusión de que eran objeto; los sectores populares que, a través de organizaciones campesinas y sindicales, demandaban el respeto a sus derechos humanos básicos; el estamento militar, en cuyo seno pervivían orientaciones diversas y hasta encontradas acerca del modo de cómo enfrentar el malestar de la sociedad — con la coacción o la apertura institucional' - ; y los grupos de poder económico - primero los cafetaleros, luego los algodoneros y cañeros, y después los industriales y banqueros-, cuyo principal interés era garantizar su riqueza y que veían con temor no sólo las movilizaciones sociales, sino las pretensiones de reforma social abanderadas por los militares jóvenes. 
En los años setenta, al hacerse presentes las organizaciones campesinas, las tensiones sociales y políticas se agudizaron, dando pie a un ambiente de efervescencia social Aunca antes visto en la historia reciente de El Salvador. Las organizaciones populares y los sectores más radicales de las clases medias optaron por la lucha armada revolucionaria; el estamento militar endureció sus posturas y se volvió más excluyente; y los grupos de poder económico no sólo clamaron por medidas de fuerza contra quienes cuestionaban su poder y riquezas, sino que ellos mismos asumieron actitudes militantes — por ejemplo con el Frente de Agricultores para la Región Oriental (FARO) o auspiciando grupos paramilitares- para enfrentar a las organizaciones campesinas, sindicales, estudiantiles y de maestros.

El desenlace de esta acumulación de conflictos irresueltos, malestar social, marginalidad, radicalismo político y autoritarismo militar fue la guerra civil que abatió al país a lo largo de la década de los ochenta y que culminó con la firma de los acuerdos de paz en enero de 1992, los cuales fueron concebidos con el propósito no sólo de terminar la guerra, sino de establecer las bases para que las tensiones que alimentaron el proceso político de El Salvador, a lo largo del siglo XX, comenzaran a ser superadas.

\subsection{Golpes de Estado y poder militar (1944-1979)}

En 1944, el general Maximiliano Hernández Martínez dejó el gobierno. Con su salida, El Salvador comenzó lo que parecía ser una nueva etapa en su vida política: la fase -atravesada por continuos golpes de Estado- de la lucha partidaria por la gestión del Estado. Esta fase coincidió con los inicios del protagonismo económico de la burguesía industrial, el cual se frustró en forma dramática con el fracaso del proyecto sustitutivo de importaciones plasmado en el Mercado Común Centroamericano (MERCOMUN), mismo que se quebró definitivamente cuando estalló la guerra entre El Salvador y Honduras en $1969^{2}$. El movimiento popular - actor fundamental en el triunfo de la huelga de brazos caídos- se aglutinó en tomo a la figura del líder populista Arturo Romero y el Partido Unión Democrática (PUD) —del que Romero era el líder-y se preparó para el proceso electoral, convocado por la Junta de Gobiemo formada tras la renuncia de Hemández Martínez, mientras que la oligarquía y los grupos sociales más conservadores se agruparon en tomo al Partido Agrario (PA). El Partido Comunista de El Salvador (PCS), principal fuerza política durante el levantamiento campesino de 1932, no tenía mucho que ofrecer en estas circunstancias dada su debilidad organizativa y la escasa base social con la que contaba ${ }^{3}$.

Diversas circunstancias llevaron a la salida del General Hernández Martínez del poder; una vez que ello se produjo, se iniciaron el en el país una secuencia de golpes de Estado, tal como a continuación se expone ${ }^{4}$ : 
(a) 21 octubre de 1944. Separado Hernández Martínez del poder, todo estaba listo en el país para dar paso al juego democrático. Sin embargo, la fuerza del movimiento popular había crecido tanto que los grupos de poder económico -especialmente los vinculados a la producción de café-, en alianza con un grupo de militares, realizaron un golpe de Estado, el 21 de octubre de 1944, con el propósito de desarticular la organización popular. La junta de gobierno que dirigía al Estado en ese momento - encabezada por el general Andrés Ignacio Menéndez- se empeñaba por lograr un proceso pacífico de transición hacia un régimen democrático en El Salvador y bajo circunstancias muy difíciles. Las condiciones económicas eran más favorables en 1944, pero el problema principal no era éste; el obstáculo que resultó insuperable fue el obstruccionismo de aquellos grupos de poder y de los militares quienes, so pena de socavar el poder político acumulado en sus manos, no estaban dispuestos a tolerar la instauración de un régimen democrático.

Es así como un grupo de militares decide, el 21 de octubre de 1944, hacerse del poder estatal, siendo el líder del movimiento golpista, el director general de la Policía Nacional (PN), coronel Osmín Aguirre y Salinas. A raíz del golpe de Estado, Menéndez fue obligado a renunciar y los miembros de la Asamblea Legislativa fueron convocados al cuartel El Zapote para presenciar la instauración de Aguirre como presidente provisional. Con Aguirre y Salinas se inauguró una modalidad de "juego electoral" en el que la oposición política no tendría posibilidades reales de acceder al poder, ya que el partido en el gobiemo utilizaría los recursos del Estado para asegurar el triunfo del candidato oficial - por lo general un militar - que sería, a su vez, el candidato de la oligarquía.

Aguirre y Salinas intentó controlar a los grupos opositores, cuyas principales figuras eran Miguel Tomás Molina y Arturo Romero, los cuales dieron vida al "romerismo", un movimiento de lucha por las libertades cívicas que logró aglutinar a los principales grupos opositores al militarismo. Además, Aguirre y Salinas hizo todo para controlar el movimiento sindical aglutinado en la Unión Nacional de Trabajadores (UNT). En diciembre de 1944, aplastó una revuelta en el barrio San Miguelito y repelió una invasión lanzada por la oposición desde Guatemala. Después de gobernar con mano dura durante casi cinco meses, convocó a elecciones para presidente, encargándose de que la victoria del candidato de la élite cafetalera, el general Salvador Castaneda Castro, fuese segura. Tal como estaba previsto, éste asumió la presidencia el 1 de marzo de 1945.

(b) 14 de noviembre de 1948: "La revolución del 48". La sucesión de. Castaneda Castro, en 1948, dio lugar a una nueva crisis política. Este pretendía reelegirse, con lo cual generó malestar e inconformidad en las filas del ejército, en sectores importantes de la burguesía industrial con una visión desarrollista y en los sectores populares que exigían reformas democráticas. Este proceso trajo como resultado la llamada "revolución del 48", misma que dio lugar a la confor- 
mación de un "Consejo de Gobiemo Revolucionario", cuya finalidad declarada era restaurar la institucionalidad perturbada por Castaneda Castro. El Consejo de Gobiemo Revolucionario preparó unas elecciones en las que salió electo, en septiembre de 1950, el coronel Oscar Osorio, candidato del nuevo partido oficial, el Partido Revolucionario de Unificación Democrática (PRUD).

Con Osorio no sólo comenzó el auge de la producción algodonera, sino que éste se esforzó por hacer del aparato estatal el promotor del crecimiento, lo cual quedó sancionado en la Constitución de 1950 en la que se justifica el nuevo rol interventor del Estado. Influido por la Constitución mexicana de 1917, el texto constitucional de 1950 prescribe lo siguiente: $(a)$ un intervencionismo estatal orientado a asegurar a todos los habitantes de El Salvador una existencia digna de un ser humano; (b) garantizar la propiedad privada en función social; (c) restringir la libertad económica en lo que se oponga al interés social; y (e) regular con carácter tutelar las relaciones entre el capital y el trabajo estableciendo, entre otras cosas, la limitación de la jomada laboral, la asociación sindical, la contratación colectiva y el salario mínimo.

(c) Los golpes de Estado de 1960-1961. Oscar Osorio fue sustituido, en los comicios presidenciales de 1956, por el candidato del PRUD, coronel José María Lemus, quien fue derrocado el 26 de octubre de 1960 por medio de un nuevo golpe de Estado en el que participan diversos sectores de la vida nacional, desde representantes de izquierda hasta importantes fracciones de la burguesía.

El gobiemo de Lemus se inició con una profundización de las reformas iniciadas con Osorio, llegando incluso a permitir el ingreso al país de todos los exiliados y prometiendo el respeto a los derechos individuales y colectivos. Una muestra de su disposición a cumplir con sus compromisos fue la derogación de la "Ley de defensa del orden democrático y constitucional", la cual tenía elementos claramente antidemocráticos. La relativa tolerancia mostrada por el régimen de Lemus estimuló la actividad organizativa sindical y política, a lo cual se sumó tanto el impacto de la revolución cubana en el ámbito universitario como el empeoramiento de la situación económica, asociada al ciclo depresivo que en ese momento afectaba al mercado internacional de café.

Ante las movilizaciones de los sindicatos, estudiantes y diversos sectores de la clase media, el gobiemo de Lemus comenzó a endurecerse: disolvió por la fuerza las concentraciones populares, asaltó la Universidad Nacional y decretó el Estado de sitio. Es en este marco que emergió el Frente Nacional de Orientación Cívica - formado por partidos políticos de centro y de izquierda, asociaciones estudiantiles y sindicatos- que preparó y ejecutó el golpe de Estado del 26 de octubre de 1960.

Tras el triunfo del movimiento golpista, se instaló una Junta de Gobierno formada por tres civiles y tres militares, que se mantuvo en el poder desde esa 
fecha hasta el 6 de febrero de 1961. Las pretensiones de esta Junta eran "restablecer la legalidad y promover un proceso democrático y constitucional, que desembocaría en un evento electoral libre". El proyecto se frustró cuando la misma fue derrocada, el 6 de febrero de 1961, por un nuevo golpe de Estado que desembocó en la instauración de un Directorio Militar. Este Directorio estuvo fuertemente influenciado por Estados Unidos, por lo cual pronto comenzó a poner en práctica una serie de reformas económicas y sociales - nacionalización del Banco Central de Reserva (BCR), leyes de protección a los campesinos, rebaja en los alquileres de las viviendas populares- con que Estados Unidos pretendía neutralizar la influencia de la revolución cubana en el continente.

En 1962, el Directorio Militar permitió la toma del poder, a través de un proceso electoral, del candidato del Partido de Conciliación Nacional (PCN) - fundado en septiembre de 1961-, coronel Julio Adalberto Rivera, quien hizo de la proclama del 6 de febrero de 1961 su programa de gobiemo. Rivera fue relevado del cargo en 1967, tras haberse desempeñado en su cargo durante un período de 5 años, por el general Fidel Sánchez Hernández, que gobemó hasta 1972. En las elecciones de este año triunfó el coronel Arturo Armando Molina, quien, tras cumplir su período de mando en el ejecutivo, dejó el poder en manos del general Carlos Humberto Romero, en 1977. En un ambiente sociopolítico sumamente violento, el gobierno de Romero se vio abruptamente interrumpido el 15 de octubre de 1979, cuando un grupo de militares jóvenes, encabezados por el coronel Amoldo Majano y el coronel Jaime Abdul Gutiérrez, promovieron un golpe de Estado e instalaron una Junta Revolucionaria de Gobiemo.

El golpe de Estado de 1979 fue el último de la larga serie de golpes de Estado que marcaron la vida política de El Salvador en el siglo XX. La coyuntura que se abrió después de octubre de 1979 fue cualitativamente distinta de las vividas con anterioridad. En 1979 se cerró una fase de la historia política de El Salvador y se abrió otra, la cual estuvo marcada por la emergencia del Frente Farabundo Martí para la Liberación Nacional (FMLN), como principal polo de oposición frente al Estado y por el estallido de una guerra civil en la que justamente se confrontaron el proyecto insurgente y el proyecto gubemamental.

En definitiva, en 1948, los militares salvadoreños intentaron impulsar un nuevo modelo de dominación política y económica centrado en una serie de reformas socioeconómicas, la modemización estatal y la coacción. Sin embargo, ese modelo adolecía de una debilidad fundamental, ya que se apoyaba en la creencia de que el café tenía una importancia primordial y que debía evitarse que la operación de ese sector se viera afectada por reformas que pudieran alterar el precario equilibrio de un país con muy poco territorio, una economía emergente y una población que crecía con gran rapidez. Los militares no pudieron caer en la cuenta de que la operación del sector cafetalero no estaba indisolublemente ligada a la oligarquía por una especie de hechizo histórico irrompible. 
Desde 1948 hasta 1979, los militares fueron incapaces de tomar conciencia sobre las necesidades sociales, políticas y económicas del país y de que éstas, a su vez, exigran no sólo reformas estructurales, sino también de una apertura política que sólo podía hacerse efectiva con el apoyo del estamento militar. No valoraron adecuadamente el poder político y económico de los grupos productores-exportadores de café, a partir del cual éstos podían impedir cualquier tipo de reforma. Los militares pudieron haber jugado un papel crucial en este proceso, tal y como lo hicieron en otros países de América Latina, pero en El Salvador no lo hicieron. En cambio, durante las tres décadas siguientes, los militares controlaron la sociedad sin llegar a dominarla. No lograron convertirse en el actor hegemónico que podría reemplazar a la oligarquía; perdieron varias oportunidades de formar coaliciones importantes e impidieron el que otros las formaran.

La pretensión de los militares de propiciar una cierta industrialización, así como una legislación que protegiera mínimamente los derechos de los trabajadores —el reformismo militar - dejó intacta la sociedad salvadoreña. Los cambios ocurridos no fueron planeados y, en la mayoría de los casos, ni siquiera previstos. Los gobiemos militares no fueron oligárquicos, pero sí beneficiaban a la oligarquía; todos esos gobiemos fueron dictaduras militares; no se permitió nunca que las instituciones republicanas prosperaran ni siquiera que operaran por algún período considerable.

\subsection{La violencia sociopolítica en la década de $\mathbf{1 9 7 0}$}

En la década de los años setenta se generó en el país una situación de intensa conflictividad social y política, la cual estuvo directamente vinculada no sólo con el empeoramiento de las condiciones de vida de los sectores populares -obreros, campesinos, vendedoras de mercados, habitantes de tugurios-, sino con la exclusión política de la que hicieron gala los gobiemos del coronel Arturo Armando Molina y el general Carlos Humberto Romero, quienes llegaron al poder tras sendos fraudes electorales, en 1972 y 1977, respectivamente. En estos dos acontecimientos políticos, tuvo un papel protagónico la Unión Nacional Opositora (UNO), integrada por el Partido Demócrata Cristiano (PDC), el Movimiento Nacional Revolucionario (MNR) y la Unión Democrática Nacionalista (UDN). La UNO, sin duda alguna el más importante frente político-electoral en la historia contemporánea de El Salvador, no sólo era expresión de las demandas de democratización y de resistencia al militarismo de la sociedad salvadoreña, sino que también representaba una salida relativamente pacífica al conflicto sociopolítico que se iba perfilando en el país ${ }^{5}$.

En el fraude electoral de 1972, la UNO llevó a José Napoleón Duarte como candidato, mientras que el Partido de Conciliación Nacional (PCN) llevó al coronel Arturo Armando Molina, quien se impuso después de una manipulación descarada de los resultados electorales. En las elecciones de 1977, la UNO parti- 
cipó con el coronel Emesto Claramout y nuevamente fue víctima de un fraude electoral que llevó al poder al candidato del PCN, el general Carlos Humberto Romero. Ante este fraude, la protesta popular no se hizo esperar. Los dirigentes de la UNO y varios miles de sus seguidores -entre los que se encontraban vendedoras de los mercados, empleados, obreros, campesinos y estudiantes- se "tomaron" la Plaza Libertad en el centro de San Salvador. En la madrugada del 28 de febrero de ese año, unidades de los cuerpos de seguridad desalojaron, con gases lacrimógenos y ráfagas de ametralladora, la concentración popular.

Fue en esta coyuntura que nacieron las "Ligas Populares 28 de febrero", una organización popular que, junto al Bloque Popular Revolucionario (BPR), el Frente de Acción Popular Unificada (FAPU), el Movimiento de Liberación Popular (MLP) y la UDN, va a ocupar un lugar protagónico en el proceso sociopolítico de los años setenta. Asimismo, dentro de las organizaciones populares, fue particularmente importante el papel de los sectores campesinos, sobre todo porque la exclusión socioeconómica que pesaba sobre ellos -agudizada por el fracaso de la transformación agraria auspiciada por Molina en 1976- los hacía más sensibles a iniciativas - como las de la Iglesia católica, a través de la Compañía de Jesús- encaminadas a fomentar la lucha por sus derechos, entre los cuales ocupaba un importante lugar el derecho a organizarse.

La Federación Cristiana de Campesinos Salvadoreños (FECCAS), fundada en 1969 como una asociación de ligas campesinas, resurgió en Aguilares a mediados de los setenta como la más fuerte organización campesina, mientras que en Usulután y Chalatenango se fundó la Unión de Trabajadores del Campo (UTC), que, nacida del trabajo pastoral, pronto derivó su accionar hacia el terreno político. Ambas organizaciones entraron en contacto en 1975 y se articularon en la Federación de Trabajadores del Campo (FTC) ${ }^{h}$, la organización campesina más fuerte que ha conocido la historia del país. A lo largo de ese año, esta organización estableció nexos con ANDES 21 de Junio (la organización de los maestros salvadoreños), con las Fuerzas Universitarias Revolucionarias 30 de Julio (FUR-30), con los Universitarios Revolucionarios 19 de Julio (UR-19), con la Unión de Pobladores de Tugurios (UPT) y con el Movimiento Estudiantil Revolucionario de Secundaria (MERS). El 5 de agosto de 1975 nació el Bloque Popular Revolucionario (BPR), como un frente popular de masas, que buscaba asegurar al movimiento popular con miras más amplias y un aporte teórico más sólido, pero enraizado en las masas campesinas, prestas a desfilar por las calles de San Salvador, conscientes de su fuerza y con la idea de que se podía nadar contra la corriente cuando el río era todavía pequeño, pero que nadie podía lograrlo si éste se volvía poderoso.

FECCAS-UTC se perfilaron como organizaciones revolucionarias, lo cual se tradujo en una combatividad creciente que se sumó al accionar políticoreivindicativo que el Bloque Popular Revolucionario (BPR) desarrollaba en di- 
versas zonas del país, sobre todo en la capital. Entre 1975 y 1979, el movimiento popular salvadoreño cobró un nuevo impulso y nuevas perspectivas al sumarse a las actividades del BPR, el Frente de Acción Popular Unificada (FAPU), fundado en 1974; las Ligas Populares 28 de Febrero (LP-28), fundadas en 1977; y el Movimiento de Liberación Popular (MLP), constituido en 1979. A lo largo de este período, el movimiento popular organizado se convirtió en un actor fundamental de la dinámica social y política en El Salvador ${ }^{7}$.

A medida que se acrecentaron las movilizaciones y acciones de hecho de las organizaciones populares - que se expresaron en movilizaciones de calle, toma de locales públicos e iglesias, así como por tomas de propiedades agrícolas-, la represión gubernamental se agudizó. Paralelamente al crecimiento y consolidación del movimiento popular, se fortaleció otro grupo de actores presentes en el quehacer sociopolítico de los años setenta: las organizaciones político-militares. Estas organizaciones, formadas por miembros radicalizados de las clases medias -especialmente por estudiantes y profesores universitarios, que en cierto modo dieron continuidad al papel protagónico de los sectores medios desde la caída del general Maximiliano Hernández Martínez-y, en menor medida, por líderes sindicales, no sólo multiplicaron sus acciones militares - secuestros de empresarios, hombres de negocios y diplomáticos, ataques a puestos militares, quemas de vehículos automotores-, sino que dieron inicio a un proceso de acercamiento a las organizaciones populares, de las cuales comenzaron a reclutar a nuevos cuadros guerrilleros.

Los grupos político-militares no sólo hicieron eco de las ideas de cambio social difundidas a partir de la revolución cubana de 1959 - rompiendo, así, con el acomodamiento sociopolítico del PCS, que básicamente se había resignado a participar en el juego electoral-, sino que justificaron su irrupción apelando tanto a la pobreza crítica en que vivían la mayor parte de salvadoreños como a la exclusión política de la que hacían gala los gobiemos militares. Integrados en su mayoría por jóvenes radicalizados de los sectores medios, los grupos político militares - una vez que consideraron que las vías legales para acceder al poder estatal se habían agotado- optaron por la lucha revolucionaria como mecanismo idóneo para enfrentar a los regímenes militares; primero, del coronel Molina; después, del general Romero; y, ya en los años ochenta —cuando se aglutinaron en el FMLN - a la Junta Revolucionaria de Gobiemo, al gobiemo de Napoleón Duarte (1984-1989) y, al cierre de la década de los ochenta y principios de la década de los noventa, al gobiemo de Alfredo Cristiani.

En El Salvador —entre 1970 y 1980 - maduraron una serie de condiciones que hicieron factible la vinculación entre el movimiento guerrillero, conformado por las organizaciones Fuerzas Populares de Liberación (FPL), Ejército Revolucionario del Pueblo (ERP), Resistencia Nacional (RN), Partido Revolucionario de los Trabajadores Centroamericanos (PRTC) y las Fuerzas Armadas de Libe- 
ración (FAL), en todas las cuales la inspiración ideológica era el marxismoleninismo y el objetivo fundamental la toma del poder político del Estado a través de la lucha armada, y el movimiento popular organizado.

Al cierre de la década de los ochenta, cada organización guerrillera había establecido nexos con un "frente de masas" determinado. Así, las Fuerzas Populares de Liberación (FPL) se vincularon con el BPR, el Ejército Revolucionario del Pueblo (ERP) lo hizo con las LP-28, las Fuerzas Armadas de la Resistencia Nacional (FARN) con el FAPU y el Partido Revolucionario de los Trabajadores Centroamericanos (PRTC) con el MLP. Por su parte, la organización guerrillera del Partido Comunista, las Fuerzas Armadas de Liberación (FAL), redefinieron sus relaciones con la Unión Democrática Nacionalista (UDN) que, de partido político, se convirtió en un frente de masas ${ }^{\sharp}$.

\subsection{Gestación y culminación de la guerra civil}

La década de los años setenta se cierra en El Salvador con una grave crisis política. El gobiemo del general Carlos Humberto Romero, pese a que puso en marcha medidas como la "Ley de defensa y garantía del orden público" - inspirada en la Doctrina de la Seguridad Nacional que los gobiernos militares suramericanos habían implementado para contener la participación sociopolítica" - , fue incapaz de controlar el desborde de las organizaciones populares. El 15 de octubre de 1979, un grupo de militares progresistas efectuaron un golpe de Estado, con pretensiones reformistas, que es cooptado por militares conservadores. Mientras tanto, las organizaciones populares radicalizaron sus demandas y, como consecuencia de ello, tuvieron que soportar los embates de la represión estatal.

La Junta Revolucionaria de Gobiemo no pudo hacer frente a la crisis política, respondiendo a las movilizaciones de las organizaciones populares con enormes cuotas de represión estatal. Cuando José Napoleón Duarte se incorporó a la Junta, en diciembre de $1980^{\prime \prime \prime}$, se iniciaron ciertas reformas económicas y sociales - reforma agraria y nacionalización de la banca y del comercio exterior-, pero las mismas fueron acompañadas con fuertes dosis de violencia estatal. Los líderes de las organizaciones populares percibieron que no había otro camino que la insurrección revolucionaria. Esta opción se concretó en la creación, en mayo de 1980, de la Dirección Revolucionaria Unificada-Político-Militar (DRU-PM), un mando conjunto que coordinaría las actividades militares de los diferentes núcleos guerrilleros y la Coordinadora Revolucionaria de Masas (CRM), que se encargaría de coordinar el trabajo político de los frentes de masas. En abril del mismo año, se constituyó el Frente Democrático Revolucionario (FDR), que aglutinó a la gran mayoría de organizaciones revolucionarias y a los partidos de oposición, instituciones, gremios y personalidades democráticas del país. En octubre de 1980, la DRU se transformó en el Frente Farabundo Martí para la Liberación Nacional (FMLN)". 
Los cuerpos de seguridad - Policia Nacional (PN), Guardia Nacional (GN) y Policía de Hacienda (PH) - y los grupos armados conocidos como "escuadrones de la muerte”, tomaron medidas de hecho en contra de los grupos organizados, líderes sindicales y campesinos, religiosos y religiosas. El golpe de más resonancia pública y de más impacto en la conciencia colectiva lo constituyó el asesinato del Arzobispo de San Salvador, Mons. Oscar Arnulfo Romero, el 24 de marzo de 1980, mientras oficiaba una misma en la capilla del Hospital "La Divina Providencia". Al asesinato de Mons. Romero siguió la muerte -n noviembre de ese mismo año- de los dirigentes del FDR, Juan Chacón, Enrique Álvarez Córdova, Manuel Franco, Enrique Escobar, Humberto Mendoza y Doroteo Hemández, quienes fueron secuestrados en un colegio católico capitalino -El Extermado de San José- mientras efectuaban una reunión de trabajo, siendo posteriormente asesinados. Estos crímenes -que se produjeron en el contexto de la muerte cotidiana de decenas de miembros y simpatizantes de las organizaciones populares, religiosos y religiosas, estudiantes, obreros y campesinos- alimenta la idea, en los involucrados en el proceso, de que la insurrección no podía esperar más.

A finales de 1980, lo grupos organizados de izquierda prepararon la llegada del año siguiente. El 10 de enero de 1981, el FMLN lanzó su "ofensiva final" (u "ofensiva general"), destinada a provocar un levantamiento popular que condujese a la caída de la Junta Revolucionaria de Gobiemo. Esta última resistió la ofensiva guerrillera y lanzó una contraofensiva militar que obligó al FMLN a internarse en las escasas zonas montañosas del país, especialmente al norte de los Departamentos de Chalatenango y Morazán. Se inició, así, la guerra civil, durante la cual se implementaron las más variadas tácticas de guerra por parte de los contendientes, con el objeto de lograr una victoria definitiva.

Durante la gestión de José Napoleón Duarte — primero en la Junta Revolucionaria de Gobierno y después como presidente constitucional (1984-1989) - se implementó la estrategia contrainsurgente denominada "Guerra de Baja Intensidad" $(\mathrm{GBI})^{12}$, la cual fue auspiciada por el gobiemo de Estados Unidos y permitió establecer una colaboración estrecha entre los ejércitos de este país y el de El Salvador. Financiamiento, pertrechos de guerra y asesoramiento militar sin límites fluyeron desde Estados Unidos hacia nuestro país; se multiplicaron los batallones de infantería de reacción inmediata - Atlacatl, Cobra, Atonal-, cuya misión era librar batallas contra las fuerzas del FMLN utilizando sus mismas técnicas y modalidades de guerra. Paralelamente a este esfuerzo militar, se ejecutaban medidas de acción cívica en los lugares de presencia guerrillera para ganar "las mentes y los corazones" de la población potencialmente simpatizante de los insurgentes, quienes terminarían como "el pez fuera del agua". Cuando Duarte dejó la presidencia, legó a Alfredo Cristiani - triunfador, como candidato del partido Alianza Republicana Nacionalista (ARENA), en las elecciones presidenciales de marzo de 1989- no sólo un expediente de buenas relaciones 
con el gobierno de Estados Unidos, sino un ejército bien entrenado y apertrechado, con grandes sumas de dinero concentradas en manos de sus principales jerarcas y con una disposición a combatir sin cansancio a todos aquellos que pudiesen ser considerados comunistas, socialistas o revolucionarios.

Mientras tanto, el FMLN desplegó todas las potencialidades forjadas durante la década anterior. Innumerables miembros de las organizaciones populares de la ciudad -muchos de ellos sobrevivientes de la represión que se desató en el país entre 1981 y 1983 - se incorporaron a sus filas. Lo mismo hicieron innumerables campesinos procedentes tanto de la FECCAS-UTC como de otras organizaciones campesinas, quienes no sólo pasaron a integrar las filas del ejército guerillero, sino que se convirtieron en su base social fundamental, su fuente de abastecimiento y la garantía de su supervivencia material. En estas condiciones, militarmente el FMLN se convirtió en una guerrilla poderosa, capaz de enfrentarse a un ejército de más de 50 mil hombres, asesorado, entrenado y financiado por Estados Unidos, en un territorio de 21 mil kilómetros cuadrados, sin grandes montañas y rodeado de países con regímenes hostiles a la lucha guerrillera (Honduras y Guatemala).

Lentamente, el FMLN comenzó un proceso de readecuaciones internas que se tradujeron en cambios significativos en sus planteamientos estratégicos, todo lo cual no fue ajeno a la reestructuración del escenario internacional propiciado por el derrumbe del bloque del Este, así como a la nueva correlación de fuerzas que al interior del país - tras doce años de una guerra civil empantanada, el cansancio social generalizado y el fuerte impacto nacional e internacional del asesinato, el 16 de noviembre de 1989 y por tropas del ejército, de los jesuitas Ignacio Ellacuría, Segundo Montes, Amando López, Juan Ramón Moreno, Ignacio Martín-Baró, Joaquín López y López, y las colaboradoras Elba Ramos y su hija Celina Maricet- se impuso entre los bandos en contienda.

En ese escenario, el FMLN transitó, no sin dificultades y largos debates ideológico-políticos ${ }^{13}$, de una lucha revolucionaria por el poder político del Estado a una lucha revolucionaria por la fundación de una nación en que la democracia social y política llegaran a ser los ejes axiales de la vida social, económica y política. Por su parte, el partido ARENA, tras dejar atrás sus antecedentes de institución vinculada a los escuadrones de la muerte a principios de los años ochenta y respaldado por su ala más moderada, encaró los desafíos que planteaba una negociación del fin de la guerra con el FMLN. La ofensiva lanzada por los insurgentes en noviembre de 1989 puso de manifiesto no sólo que un triunfo militar definitivo por cualquiera de los bandos no estaba cercano, sino que los costos económicos de la guerra hacían inviable cualquier propuesta de desartollo económico-social. El consenso sobre este punto -al igual que la buena voluntad y el empeño puestos por las comisiones negociadoras - fue lo que desencadenó la ronda de negociaciones que culminaron, en enero de 1992, con la firma de los acuerdos de paz. 
Los acuerdos de paz de Nueva York (1991) y Chapultepec (1992) constituyeron un punto de partida fundamental para el nuevo proyecto de nación - la República defnocrática- que el FMLN hizo suyo en el transcurso de los 12 años de guerra civil. También se convirtieron en el punto de partida para que el gobiemo de ARENA pudiera implementar sus planes de desarrollo económico orientados no sólo a fortalecer el sistema financiero, sino a generar confianza entre los grupos empresariales nacionales e internacionales.

\section{La reestructuración de la economía}

En la década de los cincuenta, el coronel Oscar Osorio promovió un importante proceso de diversificación agrícola, al favorecer la producción de algodón como el segundo rubro en importancia para la exportación ${ }^{14}$. El cultivo de algodón sólo pudo emerger gracias a la capacitación en el manejo y uso de fertilizantes a gran escala, así como debido a la utilización de maquinaria y equipos de - para la época y las condiciones del país- elevada tecnología. En la década siguiente, este proceso de modemización auspiciado por Osorio - y antes de su gobiemo, por la "revolución del 48"-alcanzó su mejor expresión en la dinámica industrial que se generó, y en la cual se vieron envueltos los cinco países centroamericanos.

En efecto, durante la primera década del decenio de 1960, los países de la región centroamericana dieron muestras de una notable dinámica de crecimiento económico. Este fenómeno respondió indudablemente a la participación de la producción industrial manufacturera en el intercambio comercial de la región. A partir de la segunda mitad de la década, ese ritmo comenzó a desacelerarse, lo cual llevó a la crisis del modelo regional de integración de los mercados del área centroamericana.

El grado de industrialización a nivel regional era bastante uniforme en ese entonces, teniendo El Salvador una proporción un poco más alta que la de los demás países y que el promedio regional. Hacia finales de los años sesenta, el desarrollo industrial se diferenció notablemente en América Central, ya que respecto al nivel promedio de industrialización sólo Nicaragua, Costa Rica y El Salvador pudieron sobrepasarlo. Durante los 20 años siguientes, El Salvador se perfiló como el único país que progresivamente fue perdiendo su participación porcentual en el producto manufacturero de la región, a diferencia de la evolución relativamente positiva de los demás países, especialmente de Guatemala. De este modo, el sector manufacturero salvadoreño, después de contribuir en el Producto Territorial Bruto (PTB) con el 14.6 por ciento, en 1960, y subir al 19 por ciento, en 1969 , retrocedió, en 1979 , al 14.8 por ciento's ${ }^{15}$. Los cambios más importantes en la estructura productiva del sector manufacturero salvadoreño y de la región en su conjunto-, se tradujeron en el establecimiento de industrias modernas y más dinámicas en las que ocuparon un lugar importante las indus- 
trias regionales de soda cáustica, insecticidas, clorados, llantas, fertilizantes, productos de vidrio, cables, alambre de cobre y otras, es decir, productos clasificados en los subsectores de la producción intermedia y metal-mecánica. Esta orientación de la estructura industrial trajo consigo importantes cambios en el sistema productivo, entre los cuales destacó la disminución de la participación de las materias primas en la generación del producto industrial ${ }^{1 \mathrm{~h}}$.

El esquema económico que se impuso fue el de la "sustitución de importaciones", es decir, el de producir bienes manufacturados que tradicionalmente se adquirían fuera del área centroamericana: las plantas industriales, amparadas en leyes de fomento industrial, después de realizar una labor de envasado, etiquetado o armado final reexportaban su producción, con lo cual se generó un notable incremento en el comercio intracentroamericano. De un valor de 32.7 millones de dólares en 1960, se llegó a 297.5 en 1970. En el caso de El Salvador, se pasó de 7.6 millones en 1960 a 65 millones en 1970. Asimismo, casi tres cuartas partes de los productos centroamericanos eran producidos en fábricas de propiedad norteamericana o donde el capital de esa procedencia era mayoritario. El desarrollo industrial salvadoreño de la década de los sesenta se convirtió en un aliciente para las inversiones extranjeras, en las cuales la proporción de El Salvador aumentó de 1.6 a 38.1 por ciento ${ }^{17}$. El despegue industrial de El Salvador dependía fuertemente de la consolidación del Mercado Común Centroamericano (MERCOMUN). La guerra con Honduras, en 1969, hizo colapsar los esfuerzos integracionistas $y$, con ello, se truncaron las posibilidades de afianzar sobre bases sólidas el esquema económico que la Comisión Económica para América Latina (CEPAL) estimaba viable para cada uno de los países del área.

Al quebrarse el modelo de sustitución de importaciones en el marco de la integración centroamericana, El Salvador tuvo que hacer frente a sus problemas económicos recurriendo a sus propios recursos y a los que bilateralmente pudiera obtener a partir de sus relaciones internacionales. En la década de los años setenta, lejos de significar un avance en el crecimiento del sector industrial, más bien reveló un decrecimiento leve en el mismo; mientras tanto, el sector agrícola, pese al clima de violencia sociopolítica que se vivía en el campo, no dejó de crecer, con lo cual los rasgos agrícolas de la economía salvadoreña se acentuaron. Como señala Oscar Melhado: "los setenta pueden ser caracterizados como una época de crecimiento económico, donde se mantuvo la prioridad de la industria manufacturera. Sin embargo, se incrementó la productividad en el agro. La estructura de la producción se mantuvo similar a la década anterior. No obstante el apoyo al sector industrial, no un hubo cambio sustantivo en la composición del PIB, como el experimentado en la década anterior"18.

Al cierre de la década de 1970, cambios importantes comenzaron a operar en el sector agrícola. La primera Junta Revolucionaria de Gobiemo decretó una reforma agraria, la cual fue continuada por las juntas de gobierno posteriores y 
por la administración presidencial de José Napoleón Duarte (1984-1989). Aunque la reforma agraria tuvo un impacto político que no se puede obviar - se convirtió, en ła década de los ochenta, en un componente de la estrategia de contrainsurgencia diseñada por el gobierno de Estados Unidos para El Salvador-, su impacto económico fue significativo: (a) movilizó una abundante mano de obra campesina hacia el sector cooperativo en detrimento de los cultivos tradicionales de exportación; y (b) permitió al Estado asumir la responsabilidad en la comercialización externa del café, el algodón y la caña de azúcar, restando protagonismo a los grupos oligárquicos tradicionales. En la década de los años ochenta, la reforma agraria mostró sus debilidades más profundas: era llevada adelante por motivos políticos y, además, no contaba con una base tecnológica y financiera que permitieran una modemización a fondo del sector agrícola. Asimismo, en el marco de la guerra civil, se gestó un proceso de migración de la población campesina no sólo hacia las principales ciudades del país o hacia la región centroamericana, sino hacia Estados Unidos, Canadá y Australia. El resultado de esto fue una "despoblación" del campo, con la consiguiente escasez de mano de obra.

El conjunto de estos desplazamientos de población cambiaron la fisonomía del campo salvadoreño. Su resultado más notorio fue la reducción del porcentaje de campesinos respecto de la población total: según datos oficiales (tomando en consideración únicamente los cantones), en 1971 la población rural era del 60.4 por ciento. Según el sociólogo Segundo Montes, al considerar los criterios de dependencia de actividades agrícolas para subsistir y los patrones de conducta típicamente campesina, para ese año excedía la cifra oficial, pues habían quedado de lado los municipios en los que residía una parte importante de la población con patrones de vida campesinos. Del 60 por ciento o más de la población a principios de la década de los setenta, el campesinado pasó a representar el 48 por ciento en los años noventa. Y ello sólo se explica por la dinámica de las migraciones antes señalada. En fin, algo importante ha sucedido en el agro salvadoreño en los últimos 20 años; sus repercusiones en términos de oferta de granos básicos y escasez de mano de obra agrícola ya se hacen sentir en la economía nacional, pues se añaden a la crisis generalizada del agro que tiene en jaque a las autoridades del país.

En el agro salvadoreño se ha operado un proceso de descampesinización, el cual se asocia a otro fenómeno importante: la urbanización de la vida campesina. El campo salvadoreño no sólo se ha despoblado significativamente, sino que muchas de las familias que actualmente lo habitan han mezclado sus patrones de vida campesinos - costumbres religiosas, falta de energía eléctrica y agua potable, viviendas de adobe - con patrones de vida urbanos, alentados estos últimos por los bienes (aparatos estéreos, refrigeradoras, vídeos), los ingresos en dólares provenientes de las remesas de parientes residentes en Estados Unidos (con la modificación de los patrones de consumo que ello hace posible) y los valores 
surgidos de la interacción de las familias campesinas con sus parientes en el extranjero (modas, aspiraciones de viajar, desapego de la tierra).

En fin, el declive del sector agrícola inicia aceleradamente en la década de 1980. Como indica O. Melhado: "la década de los años ochenta es un período oscuro para la producción. Se experimentó un clima permanente de violencia e inestabilidad en todo el país, pero el sector que cargó con el mayor costo fue, sin duda alguna, el agrícola. Si en algún momento se puede trazar un corte histórico de cuándo El Salvador dejó se ser un país agrícola, es, precisamente, en los años del conflicto. La agricultura había reducido durante tres décadas su proporción en el PIB. La tendencia a la disminución de la importancia de la agricultura frente a la industria, el comercio y los servicios en general se venía perfilando desde los sesenta. La guerra le coloca el sello de despedida a la importancia de la agricultura en el país"'19.

El quiebre de la agricultura como eje principal de la economía nacional trajo aparejado el fortalecimiento del comercio y las finanzas, a un grado tal que, desde finales de la década pasada, se inició un proceso de "terciarización" de la economía nacional; es decir, a un proceso en el cual el sector terciario se ha convertido en el mayor movilizador de capitales, con el subsecuente desarrollo de la infraestructura asociada al sector -imponentes centros financieros y grandes complejos comerciales. El crecimiento del sector terciario no ha sido ajeno a los reacomodos experimentados por el Estado salvadoreño, no sólo en su estructura interna -modernización estatal-, sino en su relación con la economía -reprivatización de los bienes estatizados por las juntas de gobiemo en la década de los ochenta y privatización de servicios que desde su creación fueron servidos por el Estado, como la energía eléctrica y las pensiones de retiro. Primero la administración del ex presidente Alfredo Cristiani y, después, la del presidente Armando Calderón Sol han contribuido decisivamente a afianzar el giro hacia la terciarización de la economía nacional, al asumir, cada una con matices y énfasis distintos, elementos del programa de reformas neoliberales -como la apertura externa, la reducción del Estado y la privatización de servicios públicos-, orientando los beneficios de esas reformas hacia el sector financiero $^{211}$.

En el marco de esos propósitos, ambas administraciones han impulsado una reforma del Estado con miras no sólo a hacerlo más eficiente - mediante su modemización-, sino a reducir sus presencia en la economía. Este segundo objetivo ha sido logrado, primero, reprivatizando los recursos que fueron expropiados por las juntas revolucionarias de gobiemo de los años ochenta: la banca y el comercio exterior. En segundo lugar, ambas administraciones han promovido la privatización de servicios como las telecomunicaciones y las pensiones de retiro, que desde su creación estuvieron en manos del Estado. De este modo, de un Estado grande, ineficiente e "intervencionista" se pretende pasar a un Estado 
fuerte, eficiente y garante del libre juego de las fuerzas del mercado. La reforma estatal todavía está en marcha, por lo que es imposible hacer evaluaciones definitivas sobrd su éxito o fracaso, o acerca de hacia dónde llevará al país.

\section{Democratización política}

Dos años después de iniciada la guerra civil —on las elecciones para Asamblea Constituyente de 1982 que llevaron a Álvaro Magaña a ocupar provisionalmente la presidencia de la república durante dos años-, se inició otro proceso paralelo a ella: la transición a la democracia ${ }^{21}$. Las elecciones comenzaban a abrirse paso como el mecanismo idóneo para acceder a la gestión del Estado y ARENA - tras iniciar un lento proceso de ruptura con su pasado de organización paramilitar - comenzaba a dar sus pasos como partido político. Esto último fue particularmente significativo porque con la emergencia de este partido, los grupos de poder económico volvían nuevamente al escenario político-electoral en busca de la reconquista de la hegemonía política, que estuvo en manos de los militares desde 1931. ARENA, pues, expresaba la voluntad de los grupos de poder económico de reasumir las riendas del poder político, sin intermediarios y en un escenario de conflictividad política y militar sin precedentes en la historia del país. A partir de aquellas elecciones, se iniciaron una serie de eventos electorales ininterrumpidos que llegan hasta la actualidad, y a partir de los cuales se ha consolidado la idea, entre los diversos actores sociopolíticos, de que las elecciones y sus resultados deben ser aceptados por todos. Llegar hasta este punto no fue fácil, puesto que ello requería aceptar que cualquiera que quisiera participar en las elecciones podía hacerlo y, si obtenía la victoria, nada impediría que gestionara el poder estatal.

A lo largo de los años ochenta ni los grupos de poder económico ni los sectores políticos afines a estos estaban dispuestos a aceptar la eventualidad de que el FMLN pudiera competir electoralmente o, peor aún, que pudiera obtener una victoria por esa vía. El FMLN, por su parte, no estaba dispuesto a arriesgar la seguridad de sus miembros o a descartar la posibilidad de alcanzar por la vía armada la toma total del poder. Sin embargo, la guerra civil amenazaba cada vez más con prolongarse indefinidamente, sin que ninguno de los dos bandos se impusiera sobre el otro. La ofensiva guerrillera de noviembre de 1989 y el asesinato de los jesuitas de la UCA a manos de elementos del Batallón Atlacatl, desencadenaron una ola de presiones nacionales e internacionales para que el gobierno de ARENA y el FMLN negociaran de forma definitiva el cese de las hostilidades ${ }^{22}$.

A finales de 1991, tanto el FMLN y el gobiemo salvadoreño, a cuya cabeza estaba Alfredo Cristiani, ultimaban detalles para firmar los documentos que terminarían con la guerra civil, y que sentarían las bases para una reforma política y económica del país, en orden a superar los desequilibrios estructurales que 
generaron el conflicto. El 16 de enero de 1992, los acuerdos de paz fueron firmados, con lo que se inauguró una nueva fase del proceso de transición democrática iniciada a principios de la década de los años ochenta ${ }^{23}$.

Así, desde 1992 hasta 1996 -año en que los acuerdos estaban en su fase terminal de cumplimiento-, la sociedad salvadoreña contó con una instancia normativa - los acuerdos de paz- orientada a medir los ritmos de su desarrollo sociopolítico, institucional y económico. A partir de aquel momento lo que se hiciera o dejara de hacer en país tendría que ser valorado en el contexto de los acuerdos de paz, cuyo cumplimiento constituía no sólo una obligación de los principales actores sociopolíticos firmantes de los mismos - la primera administración de ARENA y el FMLN-, sino del conjunto de la sociedad.

Tres son los temas fundamentales abordados en el Acuerdo de Paz ${ }^{24}$ : el politico, el económico-social y el judicial. En materia política, los acuerdos de paz estipularon una serie de pasos orientados a la democratización del sistema político, lo cual suponía no sólo la salida de los militares del ejercicio del poder político, sino la renuncia a las vías autoritarias como mecanismo para disputar y acceder a la gestión estatal, la aceptación del pluralismo ideológico y político, y el fortalecimiento de los partidos y del parlamento. En el terreno económico-social, estipularon una serie de mecanismos no sólo orientados hacia la reforma del modelo económico - particularmente en lo que atañe al problema agrario y la implementación de medidas tendientes a paliar los costos de los programas de ajuste estructural-, sino hacia la constitución de una instancia de discusión de los problemas estrictamente sociolaborales, como lo era el Foro de Concertación Económico-social. Finalmente, en el ámbito judicial, los acuerdos plantearon una serie de reformas, cuyo propósito era fortalecer y hacer más eficaz la administración de justicia en el país.

Cuatro años después de firmados, los acuerdos de paz fueron declarados oficialmente cumplidos. No obstante, aspectos sustantivos de estos acuerdos -como la implantación de nuevas relaciones entre trabajadores, Estado y empresarios, la depuración del sistema de justicia y la democratización de los partidos políticos- quedaron pendientes y constituyen, en la actualidad, puntos medulares entre los principales temas del debate sociopolítico salvadoreño.

En resumen, los doce años de guerra civil, los triunfos, las derrotas, los asesinatos, las persecuciones, el temor y la inseguridad, contribuyeron decisivamente a moderar las posturas más extremas y a aceptar que si no se podía exterminar al enemigo al menos había que intentar convivir con él. El FMLN decidió, al firmar los acuerdos de paz, competir electoralmente por una cuota de poder, siempre revocable a través de las umas, y el sistema político se abrió a las propuestas ideológicas y políticas del FMLN convertido en partido político. Este fue uno de los logros más importantes de los acuerdos, con los cuales la transición a la democracia dio un paso sin precedentes. Ahora existe un amplio consenso entre los más diversos grupos sociales y políticos de que la democracia es mejor que el autoritarismo. 


\section{Conclusión}

Desde la década de 1970 hasta el momento actual, se han operado importantes transformaciones en la realidad salvadoreña. La violencia sociopolítica, que abatió al país en los años setenta y se convirtió en un conflicto armado abierto en la década siguiente, dio paso a un proceso de reformas políticas de carácter democrático. Lentamente, se va construyendo un Estado de derecho, con el subsiguiente respeto a la legalidad que el mismo supone; el equilibrio de poderes, aún con limitaciones, poco a poco va permitiendo un ejercicio sin abusos del poder político. En el ámbito económico se han operado importantes cambios en la estructura productiva; El Salvador está dejando de ser un país agrícola para convertirse en un país dominado por el sector terciario. La reforma agraria de los años ochenta, la guerra civil y la implementación de una serie de reformas neoliberales por las dos administraciones de ARENA, cada una a su modo, incidieron en forma decisiva en la transformación de la economía nacional. Como complemento de estos procesos de cambio económico y político, se está operando una importante reforma del Estado, la cual está encaminada a reducir el protagonismo económico que adquirió desde 1930. De un modelo económico en el cual el Estado era un actor decisivo, estamos pasando, en la década de los noventa, a un modelo económico que exige del Estado una participación mínima. El Estado salvadoreño se va acomodando, a través de su reforma institucional, a esas exigencias.

\section{Notas}

1. Ver Castro Morán, M., Función política del ejército en el presente siglo, San Salvador, UCA Editores, 1984.

2. Ver "El conflicto Honduras-El Salvador", ECA, noviembre-diciembre, 1969, 254 255 (número monográfico).

3. Ver Salazar Valiente, M., "Crisis, dictadura, lucha...(1920-1980)", en González Casanova (Coord.), América Latina: historia de medio siglo. 2. Centroamérica, México y El Caribe, México: Siglo XXI, 1993, pp. 87-122.

4. Para esta parte nos apoyamos en González, L.A., Izquierda marxista y cristianismo en El Salvador (Un ensayo de interpretación), Tesis de maestría, FLACSO-sede México, 1994.

5. Ver González, L.A. Ibíd.; AAVV, El Salvador: año político 1971-1972, Universidad, Centroamericana "José Simeón Cañas", 1973.

6. Ver Cabarrús, C.R., Génesis de una revolución. Análisis del surgimiento de la organización campesina en El Salvador, México, Casa Chata, 1983.

7. Ver Celarié Flores, A., Surgimiento y desarrollo de las organizaciones populares en El Salvador, 1970-1979, Tesis de Maestría, FLACSO-México, 1983.

8. Ver Ellacuría, I., "La cuestión de las masas", en Ellacuría, I., Veinte años de historia en El Salvador, San Salvador: UCA Editores, 1991, pp. 777-798.

9. Ver González, L.A., "Los militares latinoamericanos", ECA, 564, octubre, 1995, pp. 1011-1016. 
10. Ver González, L.A., "Balance crítico de cuatro partidos políticos (PCN, PDC, ARENA y FMLN)", ECA, 599, septiembre, 1998, pp. 832-836.

11. Ver Benítez Manaut, R., La teoría militar y la guerra civil en El Salvador, San Salvador: UCA Editores, 1989.

12. Ver Bermúdez, L., Guerra de baja intensidad. Reagan contra Centroamérica, México: Siglo XXI, 1987.

13. Ver Villalobos, J., El estado actual de la guerra y sus perspectivas, México, Sistema de Radio Venceremos, 1986.

14. Ver Arias Peñate, S., Los subsistemas de agroexportación en El Salvador, El café, el algodón y el azúcar, San Salvador: UCA Editores, 1988.

15. Ver López, C.R., Industrialización y urbanización en El Salvador, 1969-1979, San Salvador: UCA Editores, 1979.

16. Ibíd.

17. Ibid.

18. Melhado,. O., El Salvador. Retos económicos de fin de siglo, San Salvador: UCA Editores, 1997, p. 23.

19. Ibid., pp. 23-24.

20. Ver CIDAI, "El Salvador en 1997: política, economía y sociedad", ECA, 591-592, enero-febrero, 1998, pp. 17-42.

21. Ver González, L.A., “Acerca de la transición a la democracia”, ECA, 573-574, julioagosto, 1996, pp. 631-637.

22. Ver Losada, C., "El proceso de diálogo-negociación durante el primer año de ARENA", ECA, 500-501, junio-julio, 1990, pp. 439-496.

23. Ver Córdova Macías, R., El Salvador: las negociaciones de paz y los retos de la postguerra, San Salvador, IDELA, 1993.

24. Gobiemo de El Salvador-Frente Farabundo Martí para la Liberación Nacional, "Acuerdos de Paz", ECA, enero-febrero, 1992, pp. 103-152. 